\title{
A DESCRIPTIVE STUDY TO ASSESS THE PREVALENCE OF DEPRESSION AMONG ADULTS IN SELECTED URBAN COMMUNITY, ERODE.
}

\author{
Mr. Kodeeswaran A.*| Dr. Savithri K.** \\ * Ph.D. scholar at Himalayan University at Itanagar, Arunachal Pradesh, India. \\ ** Research Guide, Himalayan University at Itanagar, Arunachal Pradesh, India \\ DOI: http://doi.org/10.47211/trr.2020.v06i01.004 \\ Received $16^{\text {th }}$ May 2020, Accepted $25^{\text {nd }}$ May 2020, Available online $25^{\text {th }}$ June 2020.
}

\begin{abstract}
Depression can be defined as an emotional reaction, altered mood state and the complex symptom accompanied by negative self-concept and lowered self esteem and is associated with regressive and self-punitive wishes. Disturbances seen in one's behaviour are named as mental illness. Behaviour includes the true components such as knowing (cognitive, thinking), feeling (affective, emotions) and doing (conative, actions). If any of these components are affected, the person may go for mental illness. Depression may range from mild and moderate states to severe states with or without psychotic features.

Depression often occurs along with other psychiatric illness. Up to 40 percent of patients with major depressive disorders have histories of one or more non mood psychiatric disorders. Unfortunately one third of all the people with depression seek help who are accurately diagnosed and obtain appropriate treatment. The WHO estimates that more than 300 million people worldwide suffer from depression. It's also the world's leading cause of disability. Depression can begin at any age and it can affect people of all races and across all socioeconomic status. Here are some of the statistics on the demographics of people with depression. Median age of depression onset is 32.5 years old. The prevalence of adults with a major depressive episode is highest among individuals between 18 and 25 years. In the total Population $11.3 \%$ of adults who report two or more races have experienced a major depressive episode in the past year, $8.7 \%$ of women have depression and $5.3 \%$ of men have depression.
\end{abstract}

Key Words: Depression, female, India, Community, depression, concept, rural.

About Authors:

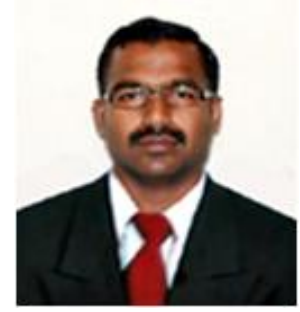

Author Mr. A. Kodeeswaran is a Ph.D. scholar at Himalayan University at Itanagar in the Indian state of Arunachal Pradesh. He has published papers and attended various Seminars and conferences.

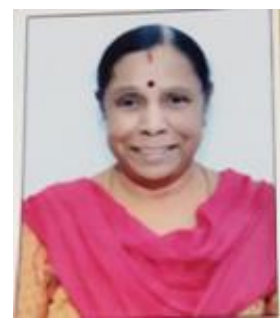

Author Dr. K. Savithri, M.Sc (N), PhD (N), is Research Guide at Himalayan University at Itanagar in the Indian state of Arunachal Pradesh. She has published papers in national and International Journals. She has attended and organised various National and International conferences and has given extensive lectures. 


\section{INTRODUCTION: -}

The National Institute of Mental Health (NIMH) estimates that 16.2 million U.S. adults had at least one major depressive episode in 2016. This represents 6.7 percent of the U.S. adult population. Depression is most common in ages 18 to 25 (10.9 percent) and in individuals belonging to two or more races (10.5 percent). Women are twice as likely as men to have had a depressive episode, according to the NIMH and the World Health Organization (WHO) Trusted Source From 2013 to 2016, 10.4 percent of women were found to have depression, compared with 5.5 percent of men, according to the CDC Trusted Source.

A survey conducted by the CDC found that the prevalence of depression decreases among adults as family income levels increase. While they don't speculate as to the cause, it may be that increased income results in less moneyrelated stress and improved access to mental health services. The survey also revealed that prevalence rates among men and women have been fairly consistent over the last decade. Research has shown that women experience depression at roughly twice the rate as men. While the exact causes of this gender disparity are unclear, this increased prevalence in women is often linked to factors such as hormones, life circumstances, and stress. Depression affects people from all walks of life, no matter their background. It can affect people of all ages as well. Unfortunately, there's still a stigma that surrounds mental health issues, and some people view disorders like depression as a weakness. But, similar to the way anyone can develop certain physical health issues; mental health issues aren't always preventable.

\section{NEED FOR STUDY:-}

Understanding the latest depression statistics could increase awareness about mental health, and recognizing how widespread it is could also help reduce the stigma - which might encourage more people to seek treatment. While anxiety disorders are the most common mental illness in the U.S., depression isn't far behind. The most recent depression statistics include as of 2017, 300 million people around the world have depression, according to the World health Organization. According to data from the 2017 National Survey on Drug Use and Health, 17.3 million adults in the United States - equalling 7.1\% of all adults in the country - have experienced a major depressive episode in the past year. Nearly $50 \%$ of all people diagnosed with depression are also diagnosed with an anxiety disorder. It's estimated that $15 \%$ of the adult population will experience depression at some point in their lifetime.

Sadness and grief are normal human emotions. We all have those feelings from time to time but they usually go away within a few days. Major depression, or major depressive disorder, however, is something more. It's a diagnosable condition that's classified as a mood disorder and can bring about long-lasting symptoms such as overwhelming sadness, low energy, loss of appetite, and a lack of interest in things that used to bring pleasure. Left untreated, depression can lead to serious health complications, including putting your life at risk. Fortunately, there are effective treatments for depression through options like therapy, medication, diet, and exercise. Specific circumstances can trigger other forms of depression or subsets of the condition.

The disorder involves the development of a manic, or energized mood, episode. Sometimes, these may be preceded or followed by episodes of depression. The presence of these episodes is what determines which type of bipolar disorder is diagnosed. When major depression or bipolar disorders are accompanied by hallucinations, delusions, or paranoia, it's called major depressive disorder with psychotic features. About 25 percent of patients who are admitted to a hospital due to depression actually have psychotic depression. 1 in 13Trusted Source people worldwide will experience a psychotic episode before age 75.

Despite all the publicity, some are still not aware of depression as it is an actual illness. This may be because we use the terms 'depressed' and 'sad' interchangeably. It's normal to feel sad or 'depressed' now and again. But clinical depression is a medical condition, not just a passing mood, and has many physical and emotional symptoms that go along with it.

\section{STATEMENT OF THE PROBLEM \\ “A DESCRIPTIVE STUDY TO ASSESS THE PREVALENCE OF DEPRESSION AMONG ADULTS IN SELECTED URBAN COMMUNITY, ERODE."}

\section{Objectives of the study:}

1. To identify the depression among the adults.

2. To determine the prevalence of depression among adults.

3. To find out the association of depression among adults and selected variables.

Hypothesis

$\mathbf{H}_{\mathbf{1}}$ : There will be a significant association between depression and selected variables 


\section{METHODOLOGY}

\section{Research Approach}

The descriptive survey approach was used to assess the prevalence of depression among adults of selected urban community.

\section{Research design}

Non-Experimental design in that descriptive design was found to be suitable for this study.

\section{Setting of the study}

The present study is conducted in Erode Urban community area.

\section{Population}

In this present study, the population represents the adults of urban community who comes under the Erode Urban community area Erode.

\section{Sample}

In this study, the sample represents the adults of Urban Community which comes under the Urban community area Erode.

\section{Sampling Technique}

The samples for the present study were taken from Erode Urban Community by using convenient sampling technique.

\section{Variables}

The demographic variables which are included in the present study are:- Age, Gender, Educational status, Occupation, Marital status, Number of children, Present role in the family, Habits, Religion, Type of family, Income, any physical illnesses, any mental illness in the family.

\section{Instrument used for this study}

A self-administered questionnaire of Beck Depression Inventory was used as an instrument for assessing the depression.

\section{RESULTS}

A descriptive survey approach was used to assess the prevalence of depression among adults in a selected urban community. Data collected from 200 samples. The majority of the respondents 55 percent were normal and without depression, 15 percent of the respondents had moderate depression followed by 5.5 percent of the respondents who had severe depression and the least 25.5 percent of the respondents had mild depression. There is a significant association found between the level of depression and selected variables like age, occupation, number of children in the family and type of family.

\section{CONCLUSION}

Depression represents one of the most profound human problems currently facing the global health care system. It is a prevalent clinical condition and is estimated to rival virtually every other known medical illness, in burden of disease morbidity early in this millennium. So this study has been conducted to assess the prevalence of depression among adults of selected urban community.

\section{REFERENCES}

1. Gail Wiscarz Stuart, Michele T. Laraia. Principles and practice of psychiatric nursing. $8^{\text {th }}$ ed. Missouri: Mosby Publication; 2005. P.330- 6.

2. Sreevani.R. A guide to mental health and psychiatric nursing. $1^{\text {st }}$ ed. New Delhi: Jaypee brothers; 2003. P.52-60.

3. Dr.Chhajer. Depression - A complete health book series. $1^{\text {st }}$ ed. New Delhi: fusion book publishers; 2005. P.13-14.

4. B.Arroll, F Good Year-Smith, N Kerse, T Fisherman, Jane Gunn. Diagnosis of depression in general practice. British Journal. 2005 Oct; 331: P.864-85.

5. Alok Jha. Depession deadlier than chronic diseases. Deccan herald. 2007 September 8; P.15 (Col.1).

6. Gregory.E.Simon, James Savarino, Belinda Operskalai, Philip.S.Wang. The American Journal of psychiatry. 2006 January; Vol-163: P.41-7.

7. Polit, Hungler BP. Nursing Research- principles and methods. $5^{\text {th }}$ ed. Philadelphia (US): Lippincott Company; 2001.

8. Best Jw. Research in education. $7^{\text {th }}$ ed. New Delhi: Prentice hall of India Pvt. Ltd; 200. P. 105.

9. Burns N, grove SK. Nursing Research. $2^{\text {nd }}$ ed. New Delhi: Harcourt India Pvt. Ltd; 2002.

10. Treece EW, Treece JW. Elements of research in nursing. $4^{\text {th }}$ ed. St. Louis: C.V. Mosby Company; 1986. 